\title{
CLINICAL PROFILE OF HAEMOPHILIA IN CHILDREN IN A TERTIARY CARE CENTRE
}

\author{
Sajini Varghese1, Naranathu Narayanannair Padmakumar ${ }^{2}$ \\ ${ }^{1}$ Assistant Professor, Department of Paediatrics, Government Medical College, Kottayam, Kerala. \\ ${ }^{2}$ Associate Professor, Department of General Medicine, Government Medical College, Kottayam, Kerala.
}

\section{ABSTRACT}

\section{BACKGROUND}

Haemophilia A and haemophilia B are the most common and serious congenital coagulation factor deficiencies. The clinical findings in haemophilia A and haemophilia B are identical. Majority of children with haemophilia show increased bleeding tendency by around one year. The hallmark of haemophilic bleeding is haemarthrosis.

\section{MATERIALS AND METHODS}

This is an observational study conducted at Government Medical College, Kottayam. Study population included all children with haemophilia less than 18 years of age attending the haemophilia clinic.

\section{RESULTS}

Total 40 children with haemophilia were enrolled in the study. Factor VIII deficiency was observed in 30 (75\%) patients (Haemophilia A), while 10 (25\%) patients were deficient in Factor IX (Haemophilia B). Majority of haemophilia patients in our study had severe deficiency.

\section{CONCLUSION}

Haemophilia A was more in our study. Bruises and ecchymoses are the most common initial presentation.

\section{KEYWORDS}

Haemophilia A, Haemophilia B, Inhibitors, Haemarthrosis, Factor Concentrate.

HOW TO CITE THIS ARTICLE: Varghese S, Padmakumar NN. Clinical profile of haemophilia in children in a tertiary care centre. J. Evolution Med. Dent. Sci. 2017;6(82):5775-5777, DOI: 10.14260/jemds/2017/1253

\section{BACKGROUND}

Haemophilia A (factor VIII deficiency) and haemophilia B (factor IX deficiency) are the most common and serious congenital coagulation factor deficiencies. The clinical findings in haemophilia A and haemophilia B are identical. ${ }^{1}$ Haemophilia occurs in approximately 1: 5,000 males with $85 \%$ having factor VIII deficiency and 10\% - 15\% having factor IX deficiency. A family history of bleeding is obtained in about two-thirds of patients with haemophilia. Females are usually carriers, transmitting the disease to their sons. ${ }^{2}$ Depending upon the factor level, haemophilia is classified into mild (5\% - 40\%), moderate $(1 \%-5 \%)$ and severe $(<$ $1 \%){ }^{3}$ Characteristic clinical presentation of haemophilia is bleeding tendency. In severe haemophilia bleeding is spontaneous, whereas in moderate, prolonged bleeding with minor trauma and in mild bleeding occurs with major trauma or surgery. $1,3,4$

Although bleeding may occur in any area of the body, the hallmark of haemophilic bleeding is haemarthrosis. The earliest joint haemorrhages appear most commonly in the ankle. In the older child and adolescent, haemarthroses of the knees and elbows are also common. ${ }^{1} \mathrm{~A}$ target joint is a joint in which 3 or more spontaneous bleeds have occurred within a

'Financial or Other Competing Interest': None.

Submission 07-09-2017, Peer Review 01-10-2017,

Acceptance 07-10-2017, Published 12-10-2017.

Corresponding Author:

Dr. Sajini Varghese,

Assistant Professor,

Department of Paediatrics,

Government Medical College, Kottayam, Kerala.

E-mail: drsajinidileep@yahoo.co.in

DOI: $10.14260 /$ jemds $/ 2017 / 1253$ consecutive 6-month period. Recurrent bleeds into joints and muscles can lead to haemophilic arthropathy and contractures. ${ }^{5}$ Intracranial, neck/throat or gastrointestinal haemorrhages are considered to be serious and lifethreatening.,6 Other sites of bleeds are skin, gum, nose and genitourinary tract.

Early recognition and proper treatment of bleeds are important for the prevention of progressive disability. The bleeding episodes are treated with factor replacement therapy with either factor VIII for haemophilia A and factor IX for haemophilia B or with cryoprecipitate or fresh frozen plasma.7,8 Of these, clotting factor concentrate is the preferred treatment option. But its most important complication is the development of inhibitors, which can neutralise the clotting factors. ${ }^{9}$ Another complication is transfusion related infections like HIV, Hepatitis B and C etc. ${ }^{10}$

Haemophilias are distributed worldwide and have heterogeneous presentation depending upon its severity. India has a very large population of patients with haemophilia; 15,000 - 16,000 persons with haemophilia are registered with the Haemophilia Federation of India. ${ }^{11}$ The present study was undertaken to identify the clinical presentation of haemophilia in children. Increased awareness among medical professionals about the varying clinical presentation of haemophilia can help in early diagnosis and management, thus preventing progressive disability and mortality.

\section{MATERIALS AND METHODS}

This is an observational study conducted at Government Medical College, Kottayam. The study was approved by the Institute of Research and Ethical Committee. Study 
population included all children with haemophilia less than 18 years of age attending the haemophilia clinic. An informed written consent was obtained first. A detailed history including patient's demographic data, type of haemophilia, severity, mode of presentation, past treatment and bleeding episodes, previous investigation reports, family history, age of onset of the disease, associated symptoms, complications and treatment history was taken. A thorough clinical examination was performed on these patients. All the results were entered on SPSS 16.0 for further analysis. Data were analysed by using SPSS statistical software (statistic package of social sciences) version 14.01 to obtain frequency tables and cross tabulation with figures to illustrate the results.

\section{RESULTS}

Total 40 children with haemophilia were enrolled in the study. Out of this factor VIII deficiency was observed in 30 (75\%) patients (Haemophilia A), while 10 (25\%) patients were deficient in Factor IX (Haemophilia B); 35 children were having severe haemophilia, whereas 5 children were moderate haemophiliac (Table 1). There were 6 children below 5 years, 15 children between 6 - 12 years, 19 children above 12 years (Table 1). Majority (47.5\%) had their first bleed during 1 - 5 year period; 16 (40\%) children developed their first clinical symptom during infancy. Most common type of first episode of bleeding observed was bruises and ecchymotic patches. Only $5(12.5 \%)$ cases presented after 5 years of age (Table 3).

Table 4 illustrates the family History of haemophilia according to which positive family history was seen in $67 \%$ of cases. Most common type of bleed observed was joint bleed (57.5\%) followed by bruises and ecchymosis (Table 5). Most common joint affected was knee followed by ankle; 10 children had haemophilic arthropathy characterised by pain and limitation of movement. Life threatening bleeds like intracranial bleed occurred in six children and fortunately all survived. Regarding the inhibitor status, 2 out of 40 children were found to be inhibitor positive (Table 6). None had transfusion related illnesses like HIV, HCV or Hepatitis B.

\begin{tabular}{|c|c|c|c|}
\hline Type & Moderate & Severe & Total \\
\hline Haemophilia A & 3 & 27 & $30(75 \%)$ \\
\hline Haemophilia B & 2 & 8 & $10(25 \%)$ \\
\hline Total & $\mathbf{5}(12.5 \%)$ & $35(87.5 \%)$ & 40 \\
\hline Table 1. Distribution of Haemophilia according to Severity \\
and Types \\
\hline
\end{tabular}

\begin{tabular}{|c|c|c|c|}
\hline Age & Haemophilia A & $\begin{array}{c}\text { Haemophilia } \\
\text { B }\end{array}$ & Total \\
\hline Up to 5 years & 3 & 3 & $6(15 \%)$ \\
\hline 6 - 12 years & 12 & 3 & $15(37.5 \%)$ \\
\hline$>12$ & 15 & 4 & $19(47.5 \%)$ \\
\hline \multicolumn{3}{|c|}{ Table 2. Age Distribution of Patient with Haemophilia } \\
\hline
\end{tabular}

\begin{tabular}{|c|c|c|c|}
\hline $\begin{array}{c}\text { Age of First } \\
\text { Presentation }\end{array}$ & Haemophilia A & Haemophilia B & Total \\
\hline$<1$ year & 13 & 3 & $19(40 \%)$ \\
\hline 1-5 year & 14 & 5 & $16(47.5 \%)$ \\
\hline > 5 years & 3 & 2 & $5(12.5 \%)$ \\
\hline \multicolumn{3}{|c|}{ Table 3. Age of First Presentation } \\
\hline
\end{tabular}

\begin{tabular}{|c|c|c|}
\hline Features & Frequency & Percentage \\
\hline Bruises and ecchymosis & 22 & $55 \%$ \\
\hline Haemarthrosis & 12 & $30 \%$ \\
\hline Scalp/ facial haematomas & 3 & $7.5 \%$ \\
\hline Prolonged bleeding from wounds & 3 & $7.5 \%$ \\
\hline Gum bleeding & 2 & $5 \%$ \\
\hline
\end{tabular}

\begin{tabular}{|c|c|c|}
\hline Family History & Yes & No \\
\hline Haemophilia A & 18 & 12 \\
\hline Haemophilia B & 6 & 4 \\
\hline Total & $\mathbf{2 4 ( 6 0 \% )}$ & $\mathbf{1 6 ( 4 0 \% )}$ \\
\hline \multicolumn{2}{|c|}{ Table 5. Family History }
\end{tabular}

\begin{tabular}{|c|c|c|}
\hline Type of Bleed & Frequency & Percentage \\
\hline Joint bleed & 23 & $57.5 \%$ \\
\hline Bruises and ecchymosis & 11 & $27.5 \%$ \\
\hline Gum bleed & 2 & $5 \%$ \\
\hline Haematoma scalp/ face & 2 & $5 \%$ \\
\hline Muscle bleed & 2 & $5 \%$ \\
\hline \multicolumn{2}{|c|}{}
\end{tabular}

Table 6. Most Common Type of Bleeding

\begin{tabular}{|c|c|c|c|}
\hline Parameters & $\begin{array}{c}\text { Haemophilia } \\
\text { A }\end{array}$ & $\begin{array}{c}\text { Haemophilia } \\
\text { B }\end{array}$ & Total \\
\hline Joint deformity & 7 & 3 & $10(25 \%)$ \\
\hline Intracranial bleed & 4 & 2 & $6(15 \%)$ \\
\hline Inhibitor & 2 & 0 & $2(5 \%)$ \\
\hline
\end{tabular}

Table 7. Complications of Haemophilia

\section{DISCUSSION}

In our study, majority (75\%) of children were found to have Haemophilia A and only (25\%) were having Haemophilia B. This is similar to the study done by Mishra et al, who observed haemophilia A (88.3\%) was the most common type of haemophilia as compared to haemophilia B. ${ }^{12}$ Agarwal et $\mathrm{al}^{13}$ also found the percentage of haemophilia A being $78.6 \%$ (236/ 300 cases). Kulkarni et al states that majority (81\%) of their haemophilia patients belonged to Haemophilia A and only $19 \%$ were having haemophilia B. ${ }^{14}$ Majority of haemophilia patients in our study had severe factor deficiency, which is similar to the findings reported by Parthiban et al ${ }^{15}$ in which both haemophilia A and B showed $66 \%$ of cases with severe factor deficiency, $26 \%$ with moderate and $8 \%$ with mild deficiency. Our findings of severity of haemophilia are also in correlation with Agarwal et al. ${ }^{13}$ The family history was present among more than half of the patients in this study. Similar percentage was reported by Parthiban et al,15 in which $52.2 \%$ of the patients had family history.

In our study $40 \%$ of children presented in infancy, $47.5 \%$ presented between 1 and 5 years and $12.5 \%$ presented after 5 years. But James et al showed $64.2 \%$ cases with severe haemophilia presented with bleeding episode before 1 month of age. ${ }^{16}$ We observed bruises and ecchymosis were the most common initial presentation. In our study, haemarthrosis was the most common (57.5\%) type of bleeding followed by skin and subcutaneous bleeds. In an Indian study by Kar et al ${ }^{17}$ in 148 patients with severe haemophilia A, knee joint was affected in all. The long-term consequences of repeated joint bleeds are the development of progressive joint damage and disability. ${ }^{18}$ We also observed haemophilic arthropathy in 10 children. One of the complications of replacement therapy is 
the development of alloantibodies called inhibitors, which can neutralise clotting factor concentrate. ${ }^{19}$ In our study, 2 (5\%) out of 40 children were found to have inhibitor. A systematic review reported the prevalence of patients with inhibitors between 5 to 7 percent with the risk of inhibitor development being higher in patients with severe rather than mild or moderate haemophilia A. ${ }^{20}$ Though patients with haemophilia are vulnerable to transfusion transmitted infections, none of our study population had the same.

\section{CONCLUSION}

Haemophilia A was more in our study. Bruises and ecchymoses are the most common initial presentation and majority of children had their first bleed during 1 - 5 year period. Haemophilia is still not a disease of public health relevance in India like other developed countries. There is very little information on the disease and its varying clinical presentation in our society. But for the persons affected, this is a lifelong problem. So there is a dire necessity to create awareness about this disease among general practitioners as well as general population, so that patients can be referred early to the haemophilia centres.

\section{REFERENCES}

[1] Scott JP, Montgomery RR. Hemorrhagic and thrombotic disorder. In: Kliegman RM, Behrman RE, Jenson BF, (eds). Nelson's text book of paediatrics. $18^{\text {th }}$ edn. Vol. 20. Philadelphia: Saunder, 2010:61-88.

[2] Bowen DJ. Haemophilia A, haemophilia B: molecular insights. Mol Pathol 2002;55(2):127-44.

[3] White GC, Rosendaal F, Aledort LM, et al. Definitions in hemophilia. Recommendation of the scientific subcommittee on factor VIII and factor IX of the scientific and standardization committee of the International Society on Thrombosis and Haemostasis. Thromb Haemost 2001;85(3):560.

[4] Guidelines for the management of Haemophilia. 2nd edn. World Federation of Hemophilia, 2012.

[5] Lee VN, Srivastava A, Nithyananth M, et al. Fracture neck of femur in haemophilia A-experience from a cohort of 11 patients from a tertiary centre in India. Haemophilia 2007;13(4):391-4.

[6] Aronstam A, Rainsford SG, Painter MJ. Patterns of bleeding in adolescents with severe haemophilia $\mathrm{A}$. $\mathrm{Br}$ Med J 1979;1(6161):469-70.

[7] Berntorp E, Shapiro AD. Modern haemophilia care. Lancet 2012;379(9824):1447-56.
[8] Bolton-Maggs PH, Pasi KJ. Haemophilias A and B. Lancet 2003;361(9371):1801-9.

[9] Ananyeva NM, Lee $\mathrm{TK}$, Jain $\mathrm{N}$, et al. Inhibitors in hemophilia A: advances in elucidation of inhibitory mechanisms and in inhibitor management with bypassing agents. Semin Thromb Hemost 2009;35(8):735-51.

[10] Philipp C. The aging patient with hemophilia: complications, comorbidities, and management issues. Hematology Am Soc Hematol Educ Program 2010;2010:191-6.

[11] World Federation of Hemophilia. Report on the Annual Global Survey 2010. Montreal, QC, Canada: World Federation of Hemophilia; 2011.

[12] Mishra S, Kumar S, Panwar A, et al. A clinical profile of hemophilia patients and assessment of their quality of life in Western Uttar Pradesh, India: an observational study. Med J DY Patil Univ 2016;9(3):320-4.

[13] Agarwal MB, Mehta BC, Bhanotra PC. Classical hemophilia a study of 236 cases from 212 unrelated families. J Assoc Physicians India 1981;29(5):385-9.

[14] Kulkarni R, Soucie JM, Lusher J, et al. Sites of initial bleeding episodes, mode of delivery and age of diagnosis in babies with haemophilia diagnosed before the age of 2 years: a report from the centers for disease control and prevention's (CDC) universal data collection (UDC) project. Haemophilia 2009;15(6):1281-90.

[15] Parthiban R, Kaler AK, Sangeeta M, et al. A clinicopathological study of haemophilia in rural set up of Karnataka. Br J Med Res 2015;6(10):948-5.

[16] Conway JH, Hilgartner MW. Initial presentation of pediatric haemophiliacs. Arch Pediatr Adolesc Med 1994;148(6):589-94.

[17] Kar A, Mirkazemi R, Singh P, et al. Disability in Indian patients with haemophilia. Haemophilia 2007;13(4):398-404.

[18] Srivastava A, Brewer AK, Mauser-Bunschoten EP, et al. Guidelines for the management of hemophilia. Haemophilia 2013;19(1):e1-47.

[19] Saint-Remy JM, Jacquemin MG. Inhibitors to factor VIII-63. immunology. In: Lee C, Berntorp E, Hoots K, (eds). Textbook of haemophilia. $2^{\text {nd }}$ edn. West Sussex: Wiley-Blackwell 2010:52-6.

[20] Wight J, Paisley S. The epidemiology of inhibitors in haemophilia A: a systematic review. Haemophilia 2003;9(4):418-35. 